\title{
Fule Park Road Survey and Design Research
}

\author{
Tingqiang Tang \\ Shanghai Art and Design Academy, Shanghai, 201808, China \\ ciam2000@sina.com
}

Key words: Investigation and Research; Fule Park; Mianyang, Sichuan

Abstract.The Fule Park, located in Mianyang of Sichuan, with rich historical heritage and local style, is an important and unique representative of Sichuan garden. The park was constructed in use of the natural landscape conditions, while its Road ingenious design, making landscapes, gardens, cities, unique combination of integration. Fule Park Road landscape construction in line with the principle of local materials, with minimal processing, full performance, texture, color, shape and other characteristics of local materials, making them the major texture factorsinto the local park landscape.

\section{Project Overview}

Fule Park is located 2 kilometers to the eastern suburbs of Mianyang City, on the Southern Section of the ancient Jianmenshudao, formerly known as Dongshan, or Qishan. Fule is known as the Mianzhou first mountain for its delicacy, elegancy and quiteness. All over the mountain, it is covered by dense pine mountains, gurgling streams and hibiscus creeks. It has become a famous tourist attraction ever since the Tang Song Dynasty, because there were many poemssuch as Du Fu, Jiang Yao, and Lu You and so on. FulePark is consisted of 10 major representative sites, just like the Han imperial garden, Yizhou Park, MianzhouBeilin, Fuller Court, and hundreds of separate spots. Gardens in the park, walking along with the view vary, makes it not only falls into the luxurious royal garden style, but also the natural landscape to basics of charm.

MianyangFulePark is a popular tourist attraction, the annual flower show held in different seasons, which attracts large numbers of tourists outside the city, is an integrated entertainment spot.

The park is located by the Seremban Creek, facing the intersection of the Fujiang River, the An Chang River and Hibiscus Creeks.,One can enjoy the beautiful scenery at the summit.

\section{Distribution of the Roads}

Fule Park Road is divided into four types:

Main road.The whole garden main road leads to the major areas of the park, the main activity of building facilities, scenic spots, offering convenient to the visitors' distribution, in pairs, smooth, winding, ups and downs, twists and organize large area landscape. The width is 4 to 6 meters. Longitudinal $8 \%$, cross slope of $1 \%$ to $4 \%$. It now appears that some of its major roads have been designed as comparatively narrow and cannot satisfy requirements of all aspects.

Secondary roads. They are the main park road to different districts, guide visitors to various attractions. The width is 2 to 4 meters.

Lanes. For park services, separate from the major tourists' paths, reducing cross, so as not to interfere with the tour. 
Marina. For the wanderings of tourists, the width is 1.2 to 2 meters, single $0.62 \sim 1 \mathrm{~m}$. Marina has become popular in recent years as foot massage fitness methods. Gravel road by walking foot massage points to achieve fitness purposes.

The park was noticed the change on the both sides of the space, density and white, left perspective lines, and arrange the appropriate buffer grass, to broaden their horizons, and in order to solve the distribution problem in holidays, and rallies the crowd.

It also reflects the objective and reasonable arrangement of the Road and Plaza scale flow density.

Road linear design. For the linear design, there is free or curve style; there is also ruled or straight fashion, tin order to form different garden styles. While using one mode, there is also another way to supplement.

Park road is also based on the function of the need to adopt the type of variable cross section. Such as different width at the turning points; benches and chairs to extend boundaries; roadside kiosks; or combination of Road and small squares and so on. Such width variations, straight and curves, actually make the roads vivid, and combine functions of recreation, residence and pedestrian, sport to one single road. Road twists by naturally favorable conditions are good places to topography and tortuous. When changes of garden space are very little, we can artificially create some conditions to go with the road turn and downs. Through the survey found: Park Road is designed to avoid multiple cross, otherwise it would lead to disorder; basically it is found that there is no small acute angle leading to difficulty in turning around of vehicles and pedestrians going by crossing the Greenland. In some triangle intersection, designers pay particular attention to the landscape design, making it unforgettable.

Road layout. Fule park road layout is based on the contents of parkland and visitors to the capacity of a given size. It goes in line with local conditions, and terrain. Road to the park landscape as mountains around the water, did not find the phenomenon of horizontal line based on the mountain surface water, multi-activity trips, facilities more content requirements; Road bend soft, greater density, but did not form a mesh grid, mountain longitudinal Road is basically 12 percent below basic, bending degree is large, density should be small, in order to form a number of loops, so as not to turn back the visitors. Mountain Road and the larger contours of bias, winding down, up and down the small slope Loop Road and downs, is very characteristic.

Park road generally do not pass through the building roads, but from the surrounding bypassed. And it masters the relationship of park road and bridge. Road Bridge is by across the surface of architectural form, its style, volume, color must coordinate with the overall design of park, and harmonize with the surrounding environment. The role of the bridge is to contact the traffic, create landscape, and organize guided tours, water separator to ensure visitors access and boat navigable water safety, beneficial to landscaping and enjoyment.

\section{Road paving and planting}

Fule Park Road paving material uses block - sand, stone, wood, hence forming a breathable upper and lower water permeable landscape - Ecology - Environmental road. In line with green ecological requirements, it creates breathable water seepage, highly conducive to the growth of trees, while reducing the ditch outside displacement, increased groundwater recharge.

The same space in the park, Yuen same direction, using a style pavement, composed the whole park, to achieve unity of purpose in seeking change. It achieved the goal of expressing the different contents, utilization and district of park road by pavement. 
Fule park lined boulevard, lined with trees and greenery planted together, free access, not by planting spacing flexible and realize the way to go in the forest mood, formed into a folder view; a certain distance in a little dense arrangement of the local form barrier, barrier scene.

It is recommended that the road should also be in line with the arrangement of the green lane horizon, turning radius and other requirements. Especially not thick bushes planted along the roadside, in case when people walk through the brakes less.

The resulting problem is the catchment, then Road unilateral style sides, about 1 meters from the road, to arrange a very shallow ditches, sink into a watery gullies rainfall, but the weather was fine when the grass one kind of ups and downs.

\section{Conclusion and Evaluation}

Road conscious planning and design through maintenance of ecological diversity to a certain extent, to achieve self-improvement environment, self-development, and its focus on sustainable landscape planning and land use premised on the versatility of the landscape, through scientifically to maintain the diversity of ecological engineering environment, play environment initiative, to achieve self-gain landscape.

Create Park in the use and utilization of the natural landscape conditions, while its Road ingenious design, making landscapes, gardens, cities, unique combination of integration, reflecting coexist with humans and nature, harmony and common prosperity of philosophy, the concept of "Heaven," the traditional philosophy.

Park Road landscape construction in line with its principle of local materials, with minimal processing, full performance, texture, color, shape and other characteristics of local materials, so that integration in the gardens surrounding environment conducive create local characteristics. So that materials rich in local characteristics works as elementary texture of the landscape of the local park.

Road through effective link between the node and the scenic, better controls environmental and tourist traffic capacity, better maintains ecological balance. Fuletourist park, to achieve sustainable development of tourism, improving environmental conditions and maintaining parks and other aspects play an important role in the ecological balance.

\section{References}

[1] Chen Xuesi. Landscape Design Mis-leadings [J] Chinese garden, 2000,3.

[2] Zhang Zong. Our garden Reference in modern Western art form [J]. Chinese garden, 2003,4.

[3] Tao Jiling.Modern value of Chinese traditional garden [D]. Chongqing University, April 2007.

[4] Han Bing Yue, ShenShixian.Park landscape design based on the geographical features [J]. Chinese garden, 2005,7.

[5] Long Bin. On the Chinese landscape culture and landscape city [J]. Huazhong Architecture, 2000,4 .

[6] Wang Xiaojun. Western modern landscape design [M]: Southeast University Press, 2000.

[7] Zhang Jiaji. Chinese gardening history [M] Taiyuan: Shanxi People's Publishing House, 2003.

[8] PengYigang.Chinese classic gardens analysis [M]. Beijing: China Building Industry Press, 2003. 